new views being opened to us of objects, which, althongh not previously unknown to us as mere external phenomena, were overlooked or neglected, because their true meaning had not been correctly seized. * * * * The beautiful discoveries of Bell, relative to the difference between sentient and motor nerves, had already presented us with an example of this kind, the result of reasoning rather than of observation; but we must say that even these are surpassed by the discoveries of Dr. Marshall Hall, whether we regard the sagacity by which they were made, or the comprehensiveness of their scope, viz., the extensive organic chain of nervous life."

Many words of the original are omitted, to avoid writing hyperbolically; a review of fourteen columns follows. English readers may also consult Stromeyer's "Beitrage," another German authority, on the same subject.

\section{THE ELECTION FOR CORONER.}

\section{To the Editor of THE LANCET.}

SIR :-Intelligence, long anticipated, has just reached me, that $\mathbf{M} r$. Adey has at length deemed it an act of policy to relin$q u i s h$ a contest (if contest it could becalled) which was altogether futile from the commencement, and which, by a fruitless and stubborn perseverance, conld only tend to expose hin to the imputation of ungenerous motives.

It is a source of no slight satisfaction to find, that my remarks on the absolute necessity of Coroners possessing adequate medico-legal information, contained in a recent number of THE LANCET, should have by chance immediately preceded an election in the metropolis of England, for the Coronership of the county of Middlesex.

I cannot permit the present opportunity to pass without cordially congratulating you upon your election to the vacant office. The great demonstration in your favour sufficiently shows that the public opinion is undergoing a considerable change, and that medical men will ere long be cousidered the most competent, and, consequently, the most eligible persons for such appointments.

Let us hope that the very sanguine expectations expressed at a late meeting of the British Medical Association, will be amply borne out, and that the result of this election, which has conferied no trifling distinction on the medical profession, will operate as a successful stimulus, which, spreading throughout the provinces, may in due time terminate in the election of medical coroners throughout the kingdom.
Your persevering exertions to promote the just interests of the medical profession require, as I have before observed, that some general demonstration of acknowleds. ment shonld be made on the part of its members; and I perfectly agree with the editor of the " Medical Anuual," that the present occasion affords a fitting opportunity for its manifestation. It is a duty, therefore, which medical men owe to themselves, to come forward, and by their subscriptions to the " Medical Coroner's Election Fund," fully prove that your services on their behalf have neither been unappreciated nor unavailing. I am, Sir, your obedient servant,

Kingston-upon-Hull, Feb. 23, 1830.

\section{GIR PHILIP CRAMPTON AND SIR} C MARSH.

WE have much pleasure in announcing that Mr. Crampton, who may justly be considered to be the representative of Irish surgery, has been raised to the dignity of Baronet of the Crnited Kingdom. As to Dr. Marsh, whose name is associated with that of Mr. Crampton, in the same Gazette, he is only known to us as a respectable, psalm-singing practitioner.

\section{TO CORRESPONDENTS.}

M.R.C.S.L. The breach of etiquette was committed in private, and is beyond the pale of our notice.

Mr. G. Bloomfield. Medical advice is never given to correspondents in the pages of this Journal.

Nr. W. H. Denham still contends, in a reply to the letter of Mr. Muriel which we have received, that the " hospital attendance" of the party whose case has been in debate, "did vot commence until October, 1827, and yet that the party was in practice in April, 1829, as a holder of the licence and diploma of the Hall and College." $\mathrm{He}$ also asks for "proof that the apprenticeship was served." This supplied, satisfactorily, Mr. Denham "w will acknowledge the erroneous nature of the information sup. plied to him."

$M r$. Laidlaw's letter received.

We fear that the communication of Censo. rius is a libel.

$J . A . S$. The information required may be found in the "Medical Almanac" of Mr. Farr, which contains, in addition, a great variety of useful matter.

The correspondence relative to the Fothergillian Medal is under consideration.

Mr. Blake's letter has been received. 